\title{
Treatment Persistence in Atrial Fibrillation: The Next Major Hurdle
}

\author{
Elaine M. Hylek ${ }^{1}$ \\ ${ }^{1}$ Department of Internal Medicine, Boston University, Boston, \\ Massachusetts, United States \\ Thromb Haemost 2018;118:2018-2019.
}

In the October issue of Thrombosis and Haemostasis, Geng et al reported treatment satisfaction with dabigatran versus warfarin among patients with atrial fibrillation (AF) in China. ${ }^{1}$ This time-intensive, patient-centred study with high completion rate of standardized telephone interviews provides high-quality data and key insights from the patients' perspectives. At 6 months, 33.5\% of patients had discontinued dabigatran compared with $19.2 \%$ for warfarin. The authors report no difference in the global Anti-Clot Treatment Scale (ACTS) Burdens score or the global ACTS Benefits score. The favourable effects of dabigatran regarding decreased concern for dietary or drug interactions and medication-related hassles were offset by the economic burden of dabigatran which is not covered by medical insurance in China. As noted by the authors, the cost of dabigatran is 70 times the cost of warfarin. Factors associated with treatment persistence included older age, longer duration of anticoagulation therapy, global ACTS Benefits score and warfarin therapy.

Other important findings of this study include the overall low proportion of patients in the registry receiving anticoagulant therapy, $27 \%$, for stroke prevention. In addition, of the 4,511 patients in the registry receiving an oral anticoagulant, only $18.5 \%(n=834)$ were ultimately enrolled in the study. Prior to propensity score matching, warfarin-treated patients were older, had higher $\mathrm{CHA}_{2} \mathrm{DS}_{2}$-VASc scores, lower education level and longer duration of anticoagulation use. The investigators did not assess changes in patient satisfaction over time. One would anticipate different attitudes among patients newly starting an anticoagulant opposed to longer term users whose mere persistence is a marker of drug tolerability and patient acceptance. The reasons for medication discontinuation are also of note with $47.6 \%$ (dabigatran-treated patients) and $42.9 \%$ (warfarin-treated patients) stopping treatment for non-bleeding adverse events, and 13.1 and $11.4 \%$, respectively, for minor bleeding.

Although initiation of anticoagulation among patients with AF remains a major global challenge, treatment persistence is

\author{
Address for correspondence Elaine M. Hylek, MD, Department of \\ Internal Medicine, Boston University, 801 Massachusetts Avenue, \\ 2nd Floor Suite, Boston, MA 02118, United States \\ (e-mail: ehylek@bu.edu).
}

an increasingly recognized major clinical hurdle. Reported rates of treatment persistence vary widely, including within country, depending on the population studied and methodology used to ascertain treatment exposure. Definitions of gaps in treatment that constitute permanent discontinuation vary across studies. In addition, observational studies restricted to new users of anticoagulant treatment provide different insights and conclusions than those studies composed of switchers, restarts or patients already established on treatment. In a retrospective study conducted in Ontario, Canada, investigators used administrative data to assess treatment discontinuation defined as a gap in dabigatran or rivaroxaban prescriptions of 14 days or greater. ${ }^{2}$ The cohort was comprised of 15,857 dabigatran-treated patients and 10,119 rivaroxaban users. At 6 months, 36.4\% of patients had discontinued dabigatran and $31.9 \%$ of patients had stopped rivaroxaban. In the United Kingdom, using the primary care Clinical Practice Research Datalink, patients newly starting anticoagulant therapy for incident AF were identified (12,307 vitamin $\mathrm{K}$ antagonist [VKA] and 914 non-VKA oral anticoagulant [NOAC]). ${ }^{3}$ Treatment persistence at 12 months for VKA was 63.6\% and $79.2 \%$ for NOACs. ${ }^{3}$ In the Dresden AF Registry, 124 of 341 patients treated with dabigatran discontinued treatment during follow-up (25.8 per 100 patient-years). ${ }^{4}$ Similar to Geng et al, the main reasons for treatment discontinuation were non-bleeding side effects. Higher rates of treatment persistence were reported from a prospective study of 1,305 patients with AF in Italy. At 12 months, $15.4 \%$ of patients stopped NOAC treatment with most of the discontinuations occurring in the first 6 months. ${ }^{5}$ In the Outcomes Registry for Better Informed Treatment of Atrial Fibrillation, 1-year persistence rates for dabigatran were lower than warfarin (adjusted persistence rates: 66\% [95\% confidence interval [CI], 60-72] vs. $82 \%$ [95\% CI, 80-84]). ${ }^{6}$ This is in contrast to a retrospective cohort analysis of a large U.S. commercial insurance database $(n=64,661)$ of patients with AF that found $47.5 \%$ of NOAC-treated patients had a proportion of received

November 9, 2018

accepted

November 9, 2018 (c) 2018 Georg Thieme Verlag KG Stuttgart · New York
DOI https://doi.org/ 10.1055/s-0038-1676101. ISSN 0340-6245. 
days covered of $\geq 80 \%$, compared with $40.2 \%$ in warfarintreated patients. ${ }^{7}$

The risk of stroke with treatment discontinuation has been shown in multiple studies including several randomized trials, the Rivaroxaban Once Daily Oral Direct Factor Xa Inhibition Compared with Vitamin K Antagonism for Prevention of Stroke and Embolism Trial in Atrial Fibrillation and the Apixaban for Reduction in Stroke and Other Thromboembolic Events in Atrial Fibrillation trial. ${ }^{8,9}$ This risk of stroke has also been shown in clinical practice, and its association with time off treatment (1-3 months: hazard ratio [HR], 1.96, 3-6 months: HR, 2.64, $\geq 6$ months: HR, 3.66; all $p<0.001)^{7}$ Given the high morbidity and mortality associated with AF-related stroke, physician and patient thresholds to discontinue treatment and physician and patient reluctance to resume an anticoagulant warrant further study. ${ }^{10}$ Geng et al found that nearly half of all discontinuations were for non-bleeding reasons. Access and out-of-pocket patient costs are major determinants of drug adherence and persistence. ${ }^{11,12}$ However, having paroxysmal versus permanent $A F$ has also been associated with treatment discontinuation. ${ }^{13}$ Certainly the mixed messages that patients receive regarding drug safety from the media warrant clarification by the medical community.

As recently demonstrated by the GARFIELD registry, progress has been made in extending appropriate treatment to patients with AF at high risk of stroke. ${ }^{14}$ Targeted educational interventions as employed in the IMPACT AF trial are proven strategies to improve global use of anticoagulants for stroke prevention in $\mathrm{AF}^{15}$ Parallel with these efforts is increasing focus on the challenge of long-term medication persistence. ${ }^{16,17}$ Perhaps stated best by Raparelli et al, 'A multi-level approach, including patients' preferences, factors determining physicians'prescribing habits and healthcare system infrastructure and support, is warranted to improve initiation and adherence of anticoagulants. ${ }^{18}$

\section{Conflict of Interest}

Research: Janssen. Advisory Board: Bayer, Boehringer Ingelheim, Bristol Myers Squibb/Pfizer, Janssen, Medtronic and Portola. Symposium: Boehringer Ingelheim and Bristol Myers Squibb/Pfizer.

\section{References}

1 Geng YP, Lan DH, Liu N, et al. Patient-reported treatment satisfaction with dabigatran versus warfarin in patients with non-valvular atrial fibrillation in China. Thromb Haemost 2018;118(10): $1815-1822$

2 Jackevicius CA, Tsadok MA, Essebag V, et al. Early non-persistence with dabigatran and rivaroxaban in patients with atrial fibrillation. Heart 2017;103(17):1331-1338
3 Martinez C, Katholing A, Wallenhorst C, Freedman SB. Therapy persistence in newly diagnosed non-valvular atrial fibrillation treated with warfarin or NOAC. A cohort study. Thromb Haemost 2016;115(01):31-39

4 Beyer-Westendorf J, Ebertz F, Förster K, et al. Effectiveness and safety of dabigatran therapy in daily-care patients with atrial fibrillation. Results from the Dresden NOAC Registry. Thromb Haemost 2015;113(06):1247-1257

5 Vedovati MC, Verdecchia P, Giustozzi M, et al. Permanent discontinuation of non vitamin $\mathrm{K}$ oral anticoagulants in real life patients with non-valvular atrial fibrillation. Int J Cardiol 2017; 236:363-369

6 Jackson LR II, Kim S, Shrader P, et al. Early therapeutic persistence on dabigatran versus warfarin therapy in patients with atrial fibrillation: results from the Outcomes Registry for Better Informed Treatment of Atrial Fibrillation (ORBIT-AF) registry. J Thromb Thrombolysis 2018;46(04):435-439

7 Yao X, Abraham NS, Alexander GC, et al. Effect of adherence to oral anticoagulants on risk of stroke and major bleeding among patients with atrial fibrillation. J Am Heart Assoc 2016;5(02):e003074

8 Patel MR, Mahaffey KW, Garg J, et al; ROCKET AF Investigators. Rivaroxaban versus warfarin in nonvalvular atrial fibrillation. NEngl J Med 2011;365(10):883-891

9 Granger CB, Alexander JH, McMurray JJ, et al; ARISTOTLE Committees and Investigators. Apixaban versus warfarin in patients with atrial fibrillation. N Engl J Med 2011;365(11):981-992

10 Lip G, Freedman B, De Caterina R, Potpara TS. Stroke prevention in atrial fibrillation: past, present and future. Comparing the guidelines and practical decision-making. Thromb Haemost 2017;117 (07):1230-1239

11 Weernink MGM, Vaanholt MCW, Groothuis-Oudshoorn CGM, von Birgelen C, IJzerman MJ, van Til JA. Patients' priorities for oral anticoagulation therapy in non-valvular atrial fibrillation: a multi-criteria decision analysis. Am J Cardiovasc Drugs 2018. Doi: $10.1007 / \mathrm{s} 40256-018-0293-0$

12 Loewen PS, Ji AT, Kapanen A, McClean A. Patient values and preferences for antithrombotic therapy in atrial fibrillation. A narrative systematic review. Thromb Haemost 2017;117(06):1007-1022

13 Aronis KN, Thigpen JL, Tripodis Y, et al. Paroxysmal atrial fibrillation and the hazards of under-treatment. Int J Cardiol 2016; 202:214-220

14 Camm AJ, Accetta G, Ambrosio G, et al; GARFIELD-AF Investigators.Evolving antithrombotic treatment patterns for patients with newly diagnosed atrial fibrillation. Heart 2017;103(04):307-314

15 Vinereanu D, Lopes RD, Bahit MC, et al; IMPACT-AF investigators. A multifaceted intervention to improve treatment with oral anticoagulants in atrial fibrillation (IMPACT-AF): an international, cluster-randomised trial. Lancet 2017;390(10104):1737-1746

16 Hess PL, Mirro MJ, Diener HC, et al; Atrial Fibrillation Think-Tank Participants. Addressing barriers to optimal oral anticoagulation use and persistence among patients with atrial fibrillation: Proceedings, Washington, DC, December 3-4, 2012. Am Heart J 2014;168(03):239-247

17 Steffel J, Verhamme P, Potpara TS, et al; ESC Scientific Document Group. The 2018 European Heart Rhythm Association Practical Guide on the use of non-vitamin K antagonist oral anticoagulants in patients with atrial fibrillation. Eur Heart J 2018;39(16):1330-1393

18 Raparelli V, Proietti M, Cangemi R, Lip GY, Lane DA, Basili S. Adherence to oral anticoagulant therapy in patients with atrial fibrillation. Focus on non-vitamin $\mathrm{K}$ antagonist oral anticoagulants. Thromb Haemost 2017;117(02):209-218 